\title{
A Systematic Review of Systematic Reviews on Blended Learning: Trends, Gaps and Future Directions
}

Muhammad Azeem Ashraf $\mathbb{D}^{\prime}$

Meijia Yang'

Yufeng Zhang'

Mouna Denden ${ }^{2}$

Ahmed Tlili $(\mathbb{D})^{3}$

Jiayi Liu ${ }^{4}$

Ronghuai Huang ${ }^{3}$

Daniel Burgos $\mathbb{D}^{5}$

'Research Institute of Education Science, Hunan University, Changsha, People's

Republic of China; ${ }^{2}$ Research Laboratory

of Technologies of Information and

Communication \& Electrical Engineering

(LaTICE), Tunis Higher School of

Engineering (ENSIT), Tunis, Tunisia;

${ }^{3}$ Smart Learning Institute, Beijing Normal University, Beijing, People's Republic of

China; ${ }^{4}$ School of Professional Studies, Columbia University, New York City, NY, USA; ${ }^{5}$ Research Institute for Innovation \& Technology in Education (UNIR iTED), Universidad Internacional de La Rioja (UNIR), Logroño, 26006, Spain
Correspondence: Ahmed Tlili

Smart Learning Institute, Beijing Normal University, Beijing, People's Republic of China

Email ahmed.tlili23@yahoo.com

\begin{abstract}
Blended Learning (BL) is one of the most used methods in education to promote active learning and enhance students' learning outcomes. Although BL has existed for over a decade, there are still several challenges associated with it. For instance, the teachers' and students' individual differences, such as their behaviors and attitudes, might impact their adoption of BL. These challenges are further exacerbated by the COVID-19 pandemic, as schools and universities had to combine both online and offline courses to keep up with health regulations. This study conducts a systematic review of systematic reviews on BL, based on PRISMA (Preferred Reporting Items for Systematic Reviews and Meta-Analyses) guidelines, to identify BL trends, gaps and future directions. The obtained findings highlight that BL was mostly investigated in higher education and targeted students in the first place. Additionally, most of the BL research is coming from developed countries, calling for crosscollaborations to facilitate BL adoption in developing countries in particular. Furthermore, a lack of ICT skills and infrastructure are the most encountered challenges by teachers, students and institutions. The findings of this study can create a roadmap to facilitate the adoption of BL. The findings of this study could facilitate the design and adoption of BL which is one of the possible solutions to face major health challenges, such as the COVID-19 pandemic.
\end{abstract}

Keywords: blended learning, hybrid learning, flipped learning, distance education, literature review, research trend

\section{Introduction}

Blended Learning (BL) is one of the most frequently used approaches related to the application of Information and Communications Technology (ICT) in education. ${ }^{1}$ In its simplest definition, BL aims to combine face-to-face (F2F) and online settings, resulting in better learning engagement and flexible learning experiences, with rich settings way further the use of a simple online content repository to support the face-to-face classes. ${ }^{2,3}$ Researchers and practitioners have used different terms to refer to the blended learning approach, including "brick and click" instruction, ${ }^{4}$ hybrid learning, ${ }^{4}$ dual-mode instruction, ${ }^{5}$ blended pedagogies, ${ }^{4}$ HyFlex learning, ${ }^{6}$ targeted learning, ${ }^{4}$ multimodal learning and flipped learning. ${ }^{3}$

Researchers and practitioners have pointed out that designing BL experiences could be complex, as several features need to be considered, including the quality of learning experiences, learning instruction, learning technologies/tools and applied pedagogies. ${ }^{7-9}$ Therefore, they have focused on investigating different BL perspectives since $2000 .^{10}$ 
Despite this 21-year investigation and research, there are still several challenges and unanswered questions related to $\mathrm{BL}$, including the quality of the designed learning materials ${ }^{9,11,12}$ applied learning instructions, ${ }^{9}$ the culture of resisting this approach, ${ }^{13,14}$ and teachers being overloaded when applying BL. ${ }^{15}$ The COVID-19 pandemic has further highlighted the challenges associated with BL. Specifically, international universities and schools worldwide had to take several actions with respect to health regulations, such as reducing classroom sizes. ${ }^{16}$ Therefore, they combined online and offline learning to maintain their courses for both on-campus and off-campus experiences. ${ }^{16}$ For instance, as a response to the effort made by the government of Indonesia to carry out physical distancing during the COVID-19 pandemic, in all domains including education, some elementary schools used BL with Moodle platform to ensure the continuity of learning. ${ }^{17}$ In this context, several teachers raised concerns about implementing $\mathrm{BL}$ experiences, such as the lack of infrastructure and competencies to do so, calling for further investigation in this regard. Several international organizations, such as UNESCO and ILO, claimed that teacher professional development for online and blended learning is one of the priorities for building resilient education systems for the future. ${ }^{18}$

Based on the background above, it is seen that there is still room for discussion of designing and implementing effective BL. Researchers have suggested that conducting literature reviews can help identify challenges and solutions in a given domain. ${ }^{19-21}$ Review papers may serve the development of new theories and also shape future research studies, as well as disseminate knowledge to promote scientific discussion and reflection about concepts, methods and practices. However, several BL systematic reviews were conducted in the literature which are of variable quality, focus and geographical region. This made the BL literature fragmented, where no study provides a comprehensive summary that could be a reference for different stakeholders to adopt BL. In this context, Smith et al mentioned that a logical and appropriate next step is to conduct a systematic review of reviews of the topic under consideration, allowing the findings of separate reviews to be compared and contrasted, thereby providing comprehensive and in-depth findings for different stakeholders. ${ }^{22}$ As BL is becoming the new normal, ${ }^{23}$ this study takes a step further beyond simply conducting a systematic review and conducts a systematic review of systematic reviews on BL. By systematically examining high-quality published literature review articles, this study reveals the reported BL trends and challenges, as well as research gaps and future paths. These findings could help different stakeholders (eg, policy makers, teachers, instructional designers, etc.) to facilitate the design and adoption of BL worldwide. Although several systematic reviews of literature reviews have been conducted in different fields, such as engineering, ${ }^{24}$ healthcare ${ }^{25}$ and tourism, ${ }^{26}$ no one was conducted on blended learning, to the best of our knowledge. It should be noted that one study was conducted in this context, but it mainly focused on the transparency of the systematic reviews that were conducted ${ }^{27}$ and was not about the BL field itself.

Guided by the technology-based learning model (see Figure 1), this study aims to answer the following six research questions:

RQ1. What are the trends of blended learning research in terms of: publication year, geographic region and publication venue?

RQ2. What are the covered subject areas in blended learning research?

RQ3. Who are the covered participants (stakeholders) in blended learning research?

RQ4. What are the most frequently used research methods (in systematic reviews) in blended learning research?

RQ5. How blended learning was designed in terms of the used learning models and technologies?

RQ6. What are the learning outcomes of blended learning, as well as the associated challenges?

The findings of this study could help to analyze the behaviors and attitudes of different stakeholders from different BL contexts, hence draw a comprehensive understanding of BL and its impact from different international perspectives. This can promote cross-country collaboration and more open BL design that more worldwide universities could be involved in. The findings could also facilitate the design (eg, in terms of the used learning models and technologies) and adoption of BL which is one of the possible solutions to face major health challenges, such as the COVID-19 pandemic.

\section{Methodology}

This study presents a systematic review of systematic review papers on BL. In particular, this review follows the PRISMA (Preferred Reporting Items for Systematic Reviews and Meta-Analyses) guidelines. ${ }^{28}$ PRISMA provides a standard peer-accepted methodology that uses a guideline checklist, which was strictly followed for this study, to contribute to the quality assurance of the revision process and to ensure its replicability. A review protocol was developed, describing the search strategy and article 


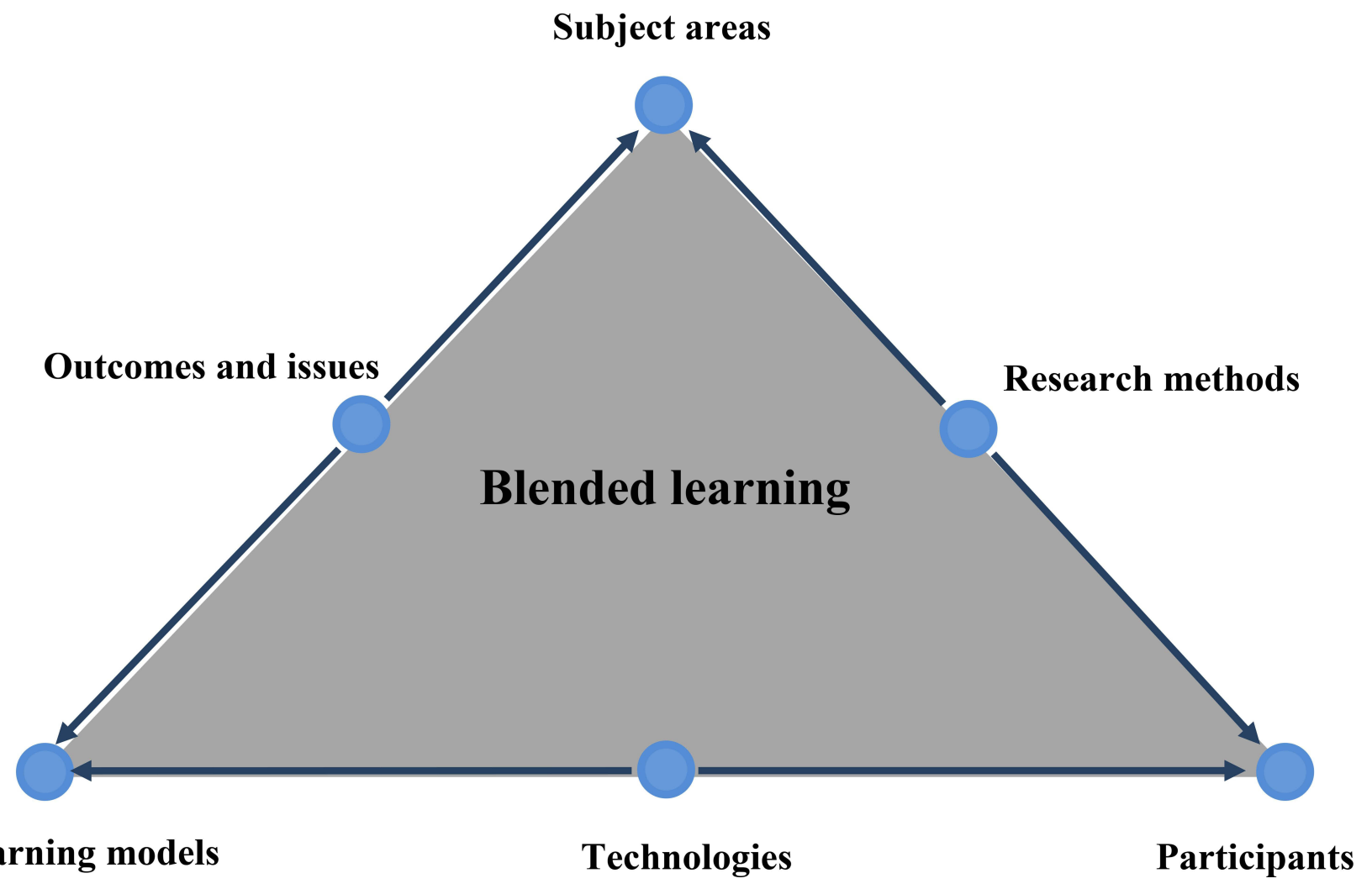

Figure I Blended learning model.

selection criteria, quality assessment, data extraction and data analysis procedures.

\section{Search Strategy and Selection Criteria}

To deal with this topic, an extensive search for research articles was undertaken in the most common and highly valued electronic databases: Web of Science, Scopus and Google Scholar, ${ }^{29}$ using the following search strings.

Search string: ((blending learning substring) AND (literature review substring))

Blended learning substring: "Blended learning" OR "blended education" OR "hybrid learning" OR "flipped classroom" OR "flipped learning" OR "inverted classroom" OR "mixed-mode instruction" OR "HyFlex learning"

Literature review substring: "Review" OR "Systematic review" OR "state-of-art" OR "state of the art" OR "state of art" OR "meta-analysis" OR "meta analytic study" OR "mapping stud*" OR "overview"

Databases were searched separately by two of the authors. After searching the relevant databases, the two authors independently analyzed the retrieved papers by titles and abstracts, and papers that clearly were not systematic reviews, such as empirical, descriptive and conceptual papers, were excluded. Then, the two authors independently performed an eligibility assessment by carefully screening the full texts of the remaining papers, based on the inclusion and exclusion criteria described in Table 1. During this phase, disagreements between the authors were resolved by discussion or arbitration from a third author. Specifically, to provide high-quality papers, this study was restricted to papers published in journals.

This research yielded a total of 972 articles. After removing duplicated papers, 816 papers remained. 672 papers were then removed based on the screening of titles and abstracts. The remaining 144 papers were considered and assessed as full texts. 85 of these papers did not pass the inclusion criteria. Thus, as a total number, 57 eligible research studies remained for inclusion in the systematic review. Figure 2 presents the study selection process as recommended by the PRISMA group. ${ }^{28}$

\section{Quality Assessment}

For methodological quality evaluation, the AMSTAR assessment tool was used. AMSTAR is widely used as a valuable tool to evaluate the quality of systematic reviews conducted in any academic field. ${ }^{30}$ It consists of 11 items 
Table I Inclusion and Exclusion Criteria

\begin{tabular}{|l|l|}
\hline Inclusion & \multicolumn{1}{|c|}{ Exclusion } \\
\hline Journal article & Conference proceeding, book series, chapter in book, books and dissertations \\
\hline Literature review & $\begin{array}{l}\text { Not a literature review or papers that do not give details about the way of conducting the } \\
\text { literature review, ie, the method }\end{array}$ \\
\hline Focus only on blended learning & $\begin{array}{l}\text { Articles that centre exclusively on other types of learning or comparison between blended } \\
\text { learning and other types of learning (eg, online learning, face to face learning) }\end{array}$ \\
\hline Available as a full text & Not available as a full text. \\
\hline Article written in English & Article in other language than English. \\
\hline
\end{tabular}

that evaluate whether the review was guided by a protocol, whether there was duplicate study selection and data extraction, the comprehensiveness of the search, the inclusion of grey literature, the use of quality assessment, the appropriateness of data synthesis and the documentation of conflicts of interest. Specifically, two authors independently assessed the methodological quality of the included reviews using the AMSTAR checklist. Items were evaluated as "Yes" (meaning the item has been properly handled, 1 point), "No" (indicating the possibility that the item did not perform well, 0 points) or "Not applicable" (in the case of performance failure because the item was not applied, 0 points). Disagreements regarding the AMSTAR score were resolved by discussion or by a decision made by a third author.

Appendix 1 presents the results of the quality assessment of the 57 systematic reviews based on the AMSTAR tool. 19 were rated as being low quality (AMSTAR score $0-4), 30$ as being moderate quality (score $5-8$ ), and eight as being high quality (score 9-11). Specifically, no study has acknowledged the conflict of interest in both the systematic review and the included studies. Also, few studies provided the list of the included and excluded studies (3 out of 57), and reported the method used to combine the findings of the studies (13 out of 57). About half of the included studies assessed the scientific quality of the included studies (25 out of 57), but all the studies fulfilled at least one quality criterion.

\section{Data Extraction}

This study adapted the technology-based learning model, ${ }^{31}$ which has been used in BL contexts, ${ }^{32,33}$ as shown in Figure 1. This model is based on six factors: subject area, learning models, participants, outcomes and issues, research methods and adopted technologies. The current study adopted most of the schemes from this model but made slight adjustments according to the features of different models in blended learning. Table 2 presents a detailed description of the coding scheme that was used in this study to answer the aforementioned research questions.

\section{Results and Discussion \\ Blended Learning Trends}

Figure 3 shows that the first two systematic reviews on $\mathrm{BL}$ were conducted in 2012. The first, by Keengwe and Kang, ${ }^{34}$ investigated the effectiveness of BL practices in the teacher education field. The second was by Rowe et $\mathrm{al},{ }^{35}$ which investigated how to incorporate $\mathrm{BL}$ in clinical settings and health education. These findings show an early interest in providing teachers with the necessary competencies and skills to use BL, as well as in enhancing health education, where students need more practical knowledge and skills that could be facilitated through BL (eg, simulation health videos, virtual labs, etc.). The number of literature reviews conducted has since increased, showing an increased interest in BL over the years. Specifically, the highest peak of literature reviews conducted on blended learning was in 2020 (16 studies). This might be due to the COVID-19 pandemic, which forced most institutions worldwide to implement BL (online merged with offline) to accommodate the needs of learners in this disruptive time. ${ }^{18}$ This has encouraged many institutions to make their own attempts to practice $\mathrm{BL}$ and thus furthered the research interest in examining the best practices of BL.

Additionally, according to the authors' affiliation countries (see Figure 4), China and the United States have the highest number of publications, with nine and seven studies respectively. This could be explained by the continuous rapid evolution of the technological education 


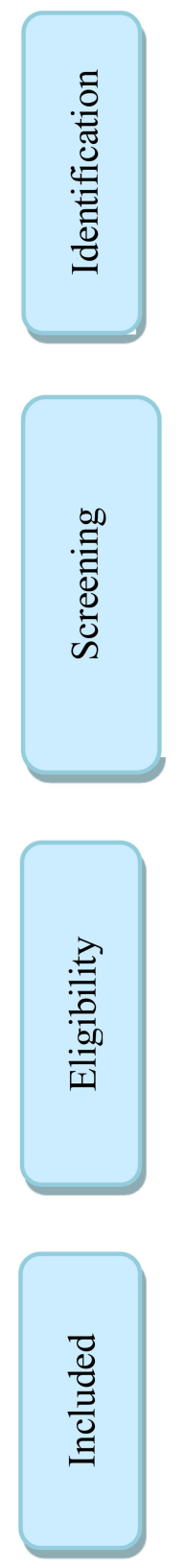
Records identified through database searching: Web of Science (510), Scopus (412), WoS (45), additional from references $(n=5)(\mathrm{N}=\mathbf{9 7 2})$

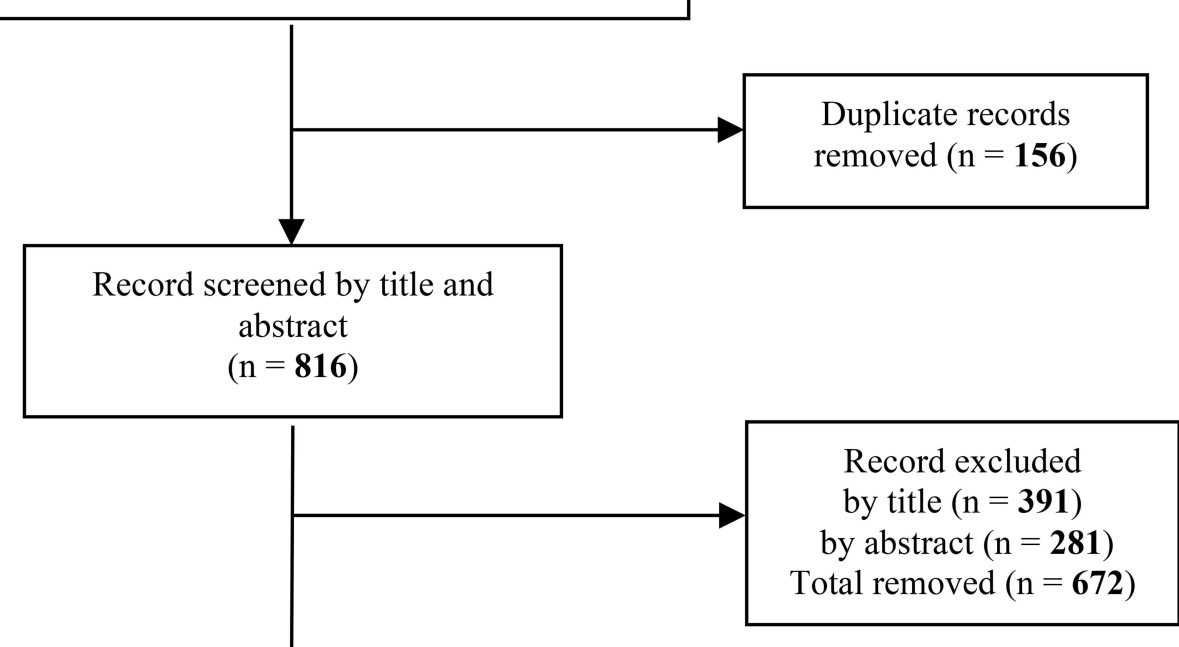

Figure 2 Flowchart of the systematic review process.

industry in both China and the United States, ${ }^{36}$ which has made researchers and educators innovate to provide more flexible learning experiences by combining both online and offline environments. ${ }^{37}$ This could also be explained by the number of blended learning policies that have been issued in these two countries to facilitate blended learning adoption. ${ }^{38,39}$

Interestingly, while several studies are from Europe (eg, Belgium, the UK, Italy, etc.), there are very few studies from the African and Arab regions. Similarly, in $\mathrm{BL}$ contexts, Birgili et $\mathrm{al}^{40}$ conducted a systematic review about flipped learning between 2012 and 2018; they found very few studies coming from Africa. This indicates a trend where countries with more sufficient educational resources and infrastructure are exposed to more chances to develop BL environments and experiences. These findings call for more cross-country collaboration to facilitate the implementation of BL in the countries that have limited knowledge or infrastructure related to BL. For instance, such a collaboration could cover BL policies, ICT trainings and the development of educational resources and technologies. 
Table 2 The Coding Scheme for Analyzing the Collected Papers

\begin{tabular}{|c|c|c|}
\hline Items & Description & Coding \\
\hline Year of publication & Year of publication & Year of publication \\
\hline Nationalities of first authors & Authors names & Authors names \\
\hline Journal & Journal name & Journal name \\
\hline Subject area & $\begin{array}{l}\text { The area of the conducted review (eg, } \\
\text { mathematics, medicine or engineering) }\end{array}$ & $\begin{array}{l}\text { The scheme of subject area refers to the general area } \\
\text { where the study was conducted }\end{array}$ \\
\hline Research methods & $\begin{array}{l}\text { Whether the review is a systematic review or a } \\
\text { meta-analysis }\end{array}$ & $\begin{array}{l}\text { Since this paper is a literature review of literature reviews, } \\
\text { the scheme of research methods mainly refers to the type } \\
\text { of literature review including systematic review and meta- } \\
\text { analysis review }\end{array}$ \\
\hline Participants & $\begin{array}{l}\text { Participants of the included studies (eg, students, } \\
\text { teachers, health professionals, or institution staff) }\end{array}$ & $\begin{array}{l}\text { The scheme of participants was classified according to } \\
\text { today's common education stages }\end{array}$ \\
\hline Educational level & $\begin{array}{l}\text { The participant educational level (eg, primary, } \\
\text { secondary, and higher education) }\end{array}$ & $\begin{array}{l}\text { The scheme of educational level was classified according to } \\
\text { today's common educational stages }\end{array}$ \\
\hline Learning models & The different blended learning models & $\begin{array}{l}\text { Blended learning model classification includes Flipped } \\
\text { model, Mixed model, Flex model, Supplemental model, } \\
\text { Online-practicing model, and Station rotation model } \\
\text { (Alammary 2019; Coyle et al 2019) }\end{array}$ \\
\hline Technologies & $\begin{array}{l}\text { The different technologies used and the } \\
\text { interventions to design the online and off-line } \\
\text { versions in each blended learning model }\end{array}$ & $\begin{array}{l}\text { The technologies used (eg, online learning platform, videos, } \\
\text { Facebook, video projector, etc.) }\end{array}$ \\
\hline Outcomes and issues & $\begin{array}{l}\text { The research issues refer to blended learning } \\
\text { outcomes and issues }\end{array}$ & $\begin{array}{l}\text { This study referred to the scheme of Majuri et al, which } \\
\text { categorizes learning outcomes into psychological outcomes } \\
\text { (eg, perception, engagement, etc.) and behavioural } \\
\text { outcomes (eg, academic performance, interaction with the } \\
\text { system, etc.) }\end{array}$ \\
\hline
\end{tabular}

Finally, the 57 reviews were published in 44 journals. Figure 5 shows the journals that have at least two publications. Education and Information Technologies has the highest number of publications (six studies), followed by Interactive Learning Environments (four studies) and Nurse Education Today (four studies). These journals are mostly from the educational technology and health fields.

\section{Subject Area}

Figure 6 shows that most of the literature review studies $(n=21)$ did not mention the covered subject area and discussed $\mathrm{BL}$ in general. For example, Wang et al proposed a complex adaptive systems framework to conduct analysis on BL literature. $^{41}$ This shows that, despite the popularity of BL, which has existed for a decade, educators and researchers are still finding it to be a complex concept that needs further investigation regardless of the subject. ${ }^{2}$
Other studies considered BL as being context-dependent, ${ }^{42}$ investigating it from different subject areas, namely health (14 studies), STEM (five studies) and language (three studies). This could be explained by these three subjects requiring a lot of practical knowledge, such as communication and pronunciation, programming or physical treatments, where the BL concept could provide teachers with a chance to be more innovative and offer students the possibility of practicing this practical knowledge online by using virtual labs or online virtual programming emulators, for instance. Walker et $\mathrm{al}^{43}$ and Yeonja et $\mathrm{al}^{44}$ found that $\mathrm{BL}$ is considered to be crucial for health students, and health educators have tried to integrate a wide range of advanced technology and learning tools to enhance their skill acquisition.

From these findings, it can be deduced that more research should be conducted to investigate how BL is conducted in other subject areas that are considered crucial for student 


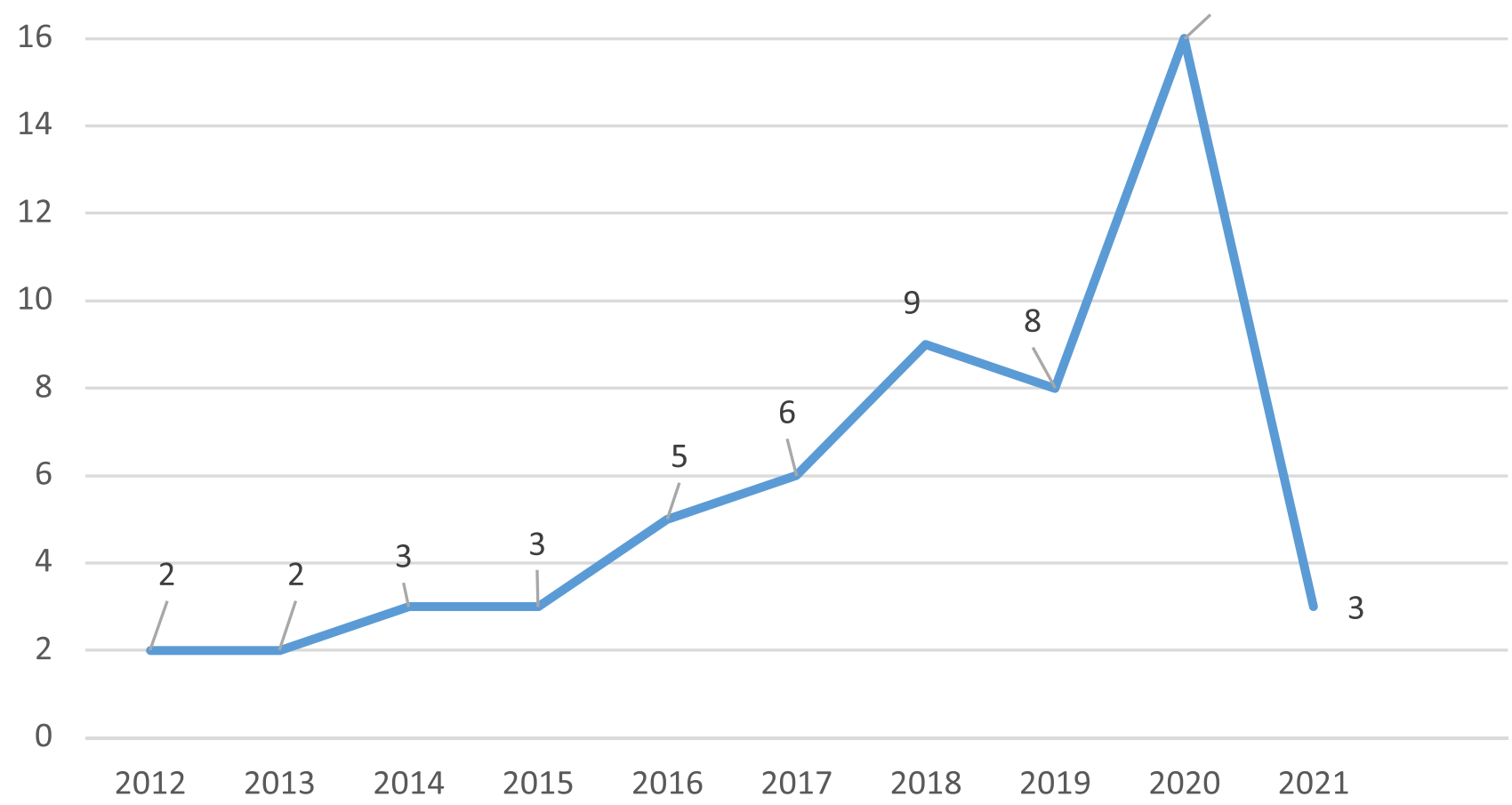

Figure 3 Distribution of studies by publication year.

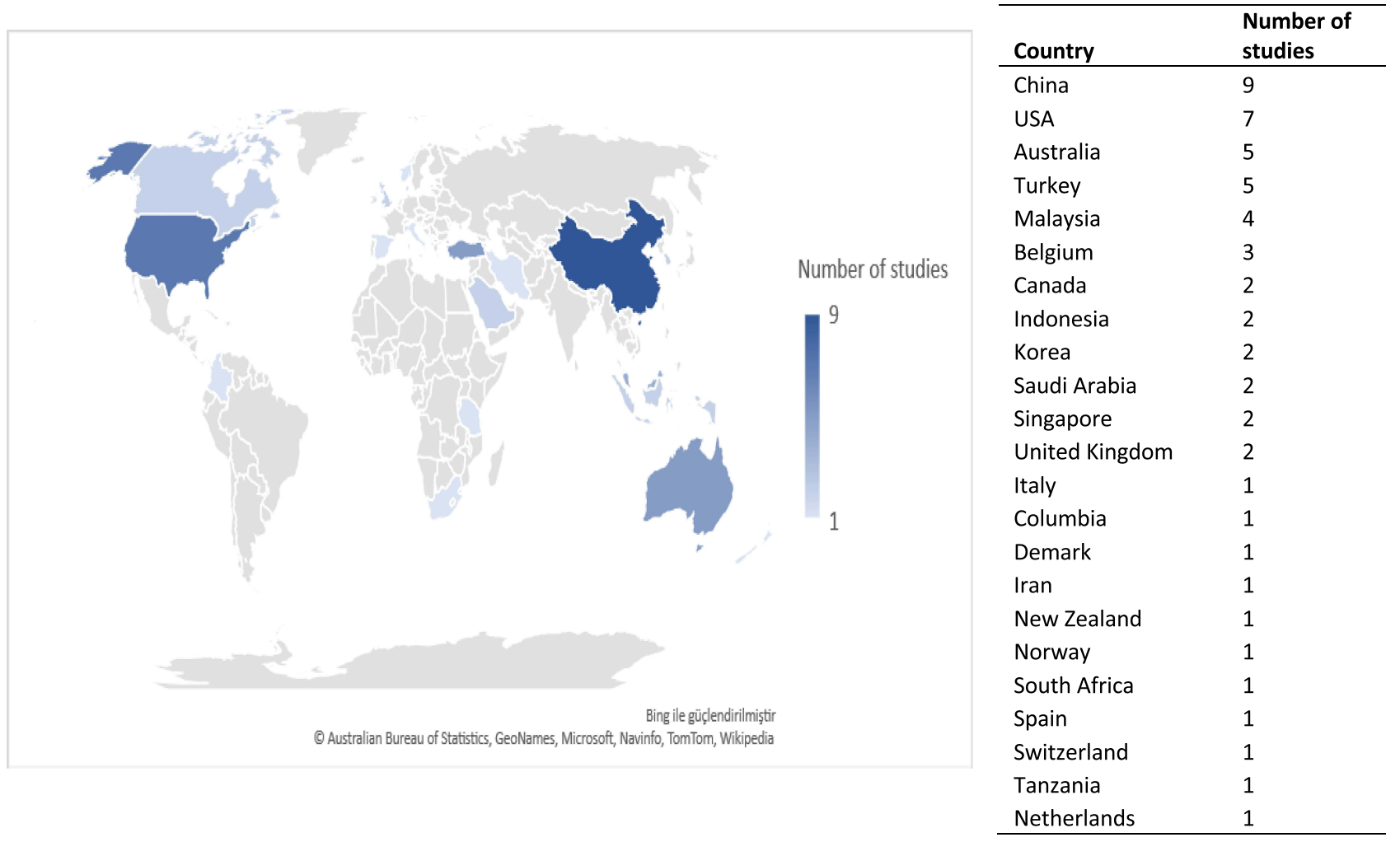

Figure 4 Distribution of studies per country. 


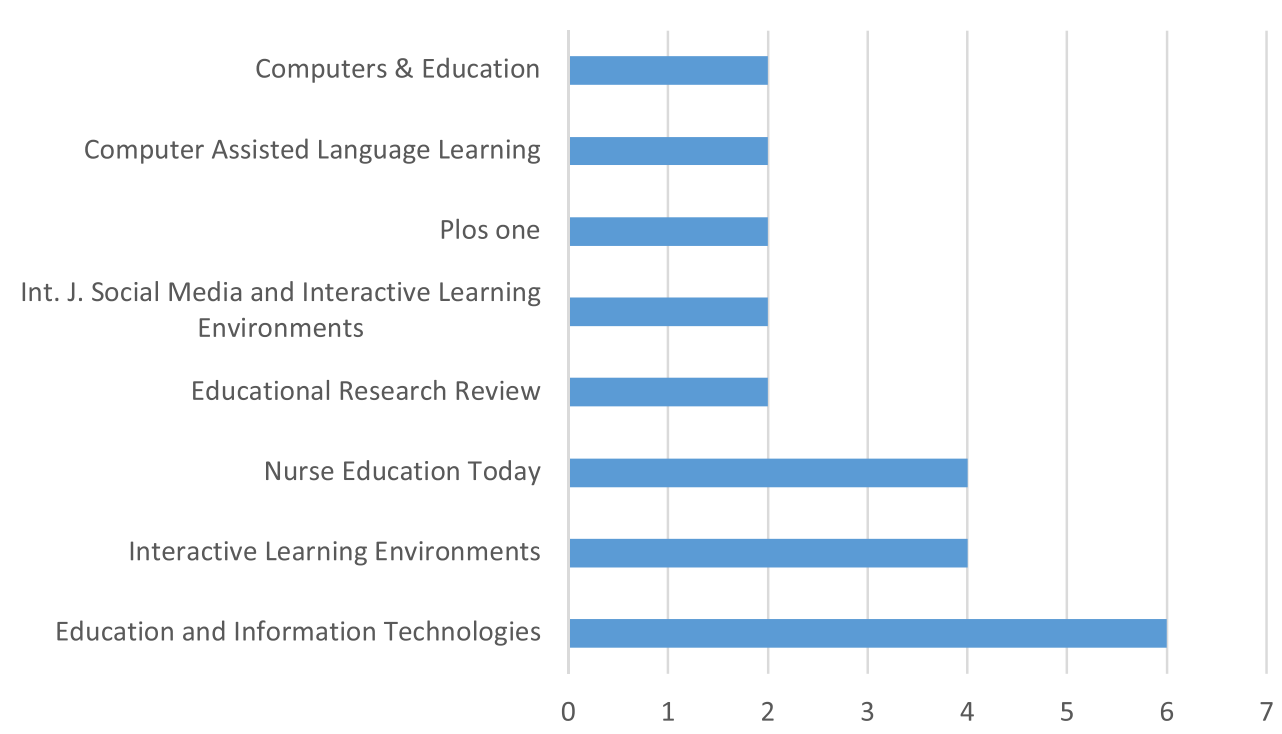

Figure 5 Distribution of studies by publication venue.

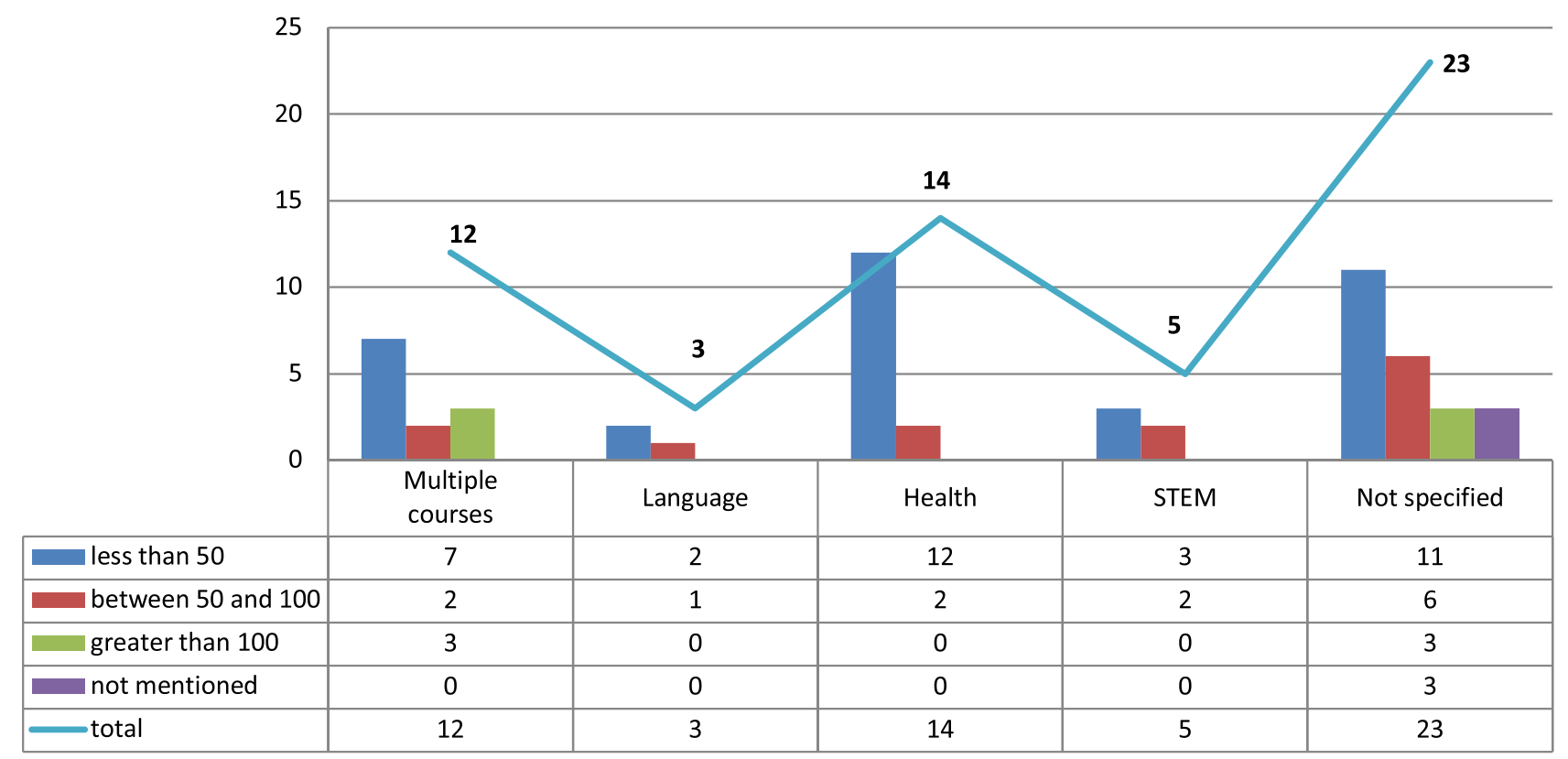

Figure 6 Distribution of studies by subject area.

performance assessment, such as mathematics. This could help researchers and practitioners compare the different $\mathrm{BL}$ design and assessment approaches in different subjects and come up with personalized guidelines that could help educators implement their BL in a specific subject. In this context, studies have pointed out that teachers are willing to implement BL in their courses but do not know how. ${ }^{45}$ Additionally, as shown in Figure 6, most of the conducted literature reviews covered limited number of studies (less than 50). Therefore, the future literature reviews on BL should cover more studies (more than 50) to have an in-depth and broad view of how BL is being implemented in different contexts by different researchers.

\section{Participants}

As Figure 7A shows, the most targeted participants by the review studies were students $(n=42)$ followed by teachers ( $n$ $=13$ ) and then working adults, health professionals and researchers (one study for each). This analysis shows that none of the review studies have targeted major players in the adoption of BL, such as policy makers. Owston stated that policies on different levels (eg, institutions, faculties, 
A

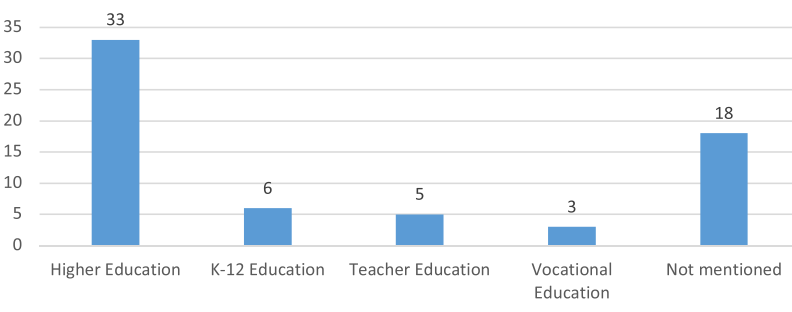

Figure 7 (A) Distribution by educational level. (B) Distribution by participants.

technology use, data collection procedures, learning support, etc.) are crucial to advancing the adoption of BL for future education. ${ }^{38}$ Therefore, to advance $\mathrm{BL}$ adoption worldwide, more reviews about $\mathrm{BL}$ policies and the focus of these policies - including copyright, privacy and data protection, and others, ${ }^{46,47}$ - should be investigated to develop a BL policy framework to which everyone could refer.

Figure 7B, on the other hand, shows that most of the review studies $(\mathrm{n}=33)$ focused mainly on higher education, followed by $\mathrm{K}-12$ (six studies) and teacher education (five studies). Interestingly, these findings are in line with two older studies that were conducted in 2012 (Halverson et al) ${ }^{48}$ and 2013 (Drysdale et al), ${ }^{49}$ where they found that BL is mostly applied in higher education. These findings clearly show that, despite the long period of time since 2012, the research setting of BL application has not changed, which calls for more serious efforts and research about BL design in other contexts, such as $\mathrm{K}-12$. Especially since younger students might lack the appropriate self-regulation skills compared to older students that can help them adopt $\mathrm{BL},{ }^{50}$ more support should also be provided accordingly. Additionally, as few studies focused on teacher education, more research should investigate how to harness the power of BL for teacher professional development. There are limited empirical findings on $\mathrm{BL}$

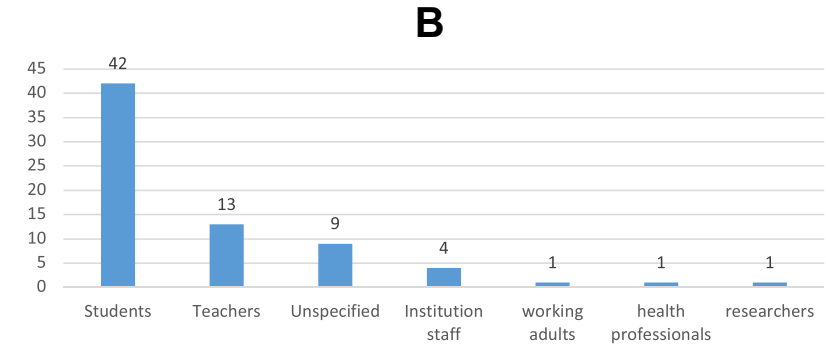

for teacher professional development,,$^{34,51-53}$ calling for more investigation in this context.

\section{Research Method}

Table 3 shows that most reviews conducted were systematic reviews $(n=47)$. As researchers note, systematic literature reviews are usually composed with a clearly defined objective, a research question, a research approach and inclusion and exclusion criteria. ${ }^{5-56}$ Through systematic review, researchers can come to a qualitative conclusion in response to their research question. Only seven reviews conducted meta-analysis to assess the effect size and variability of BL and to identify potential causal factors that can inform practice and further research. Finally, three studies used both systematic reviews and meta-analysis in their studies, which can quantitatively synthesize the results in an even more comprehensive way. For instance, Liu et $\mathrm{al}^{57}$ first reviewed the literature of the effectiveness of knowledge acquisition in healthsubject learners and then conducted a meta-analysis to show that BL had a significant larger pooled effect size than non-BL health-subject learners. In this way, researchers are able to address the extent to which BL is truly effective in the learning. ${ }^{57}$ Considering that only three review papers conducted both systematic review and

Table 3 Distribution of Studies by Research Method and Subject Area

\begin{tabular}{|l|c|c|c|c|}
\hline Subject Area & Systematic Review & Meta-Analysis Review & Systematic and Meta-Analysis Review & Total \\
\hline Multiple Courses & 10 & 0 & 2 & 0 \\
\hline Language Learning & 2 & I & I & 3 \\
\hline Health & II & I & 0 & 14 \\
\hline STEM & 4 & 3 & 0 & 5 \\
\hline Uncategorized & 20 & 7 & 3 & 57 \\
\hline Total & 47 & & & 5 \\
\hline
\end{tabular}


meta-analysis, we must again address the usefulness of quantitative analysis. There are still many unanswered questions that could be addressed in a better way using quantitative analysis. Therefore, future research should consider conducting more meta-analysis in order to provide a better understanding of the nuanced effects of BL.

\section{Design (Learning Models and Technologies)}

Figure 8 shows that the majority of review studies (33 out of 57) discussed BL as a generic concept and did not mention any specific model. Additionally, the flipped model was the most frequently implemented model, mentioned by 27 review studies. This model is designed based on three stages: pre-class, in-class and post-class (optional). In the pre-class stage, the students engage with the course content through online resources, so that they spend in-class time doing practical activities and having discussions. Then, in the post-class stage, teachers can assess the students' perceptions and performance in the flipped course. ${ }^{32}$

The second most frequently used models were the station rotation model and the flex model (each mentioned by three studies). In the station rotation model, the student can rotate at fixed points of time (on a fixed schedule or at the teacher's discretion) between different stations, at least one of which is an online learning station). ${ }^{58}$ For instance, the students can rotate between face-to-face (F2F) instruction, online instruction and collaborative activities. The flex model, on the other hand, relies entirely on online materials and student self-study, with the availability of F2F teachers when needed. ${ }^{59}$

Two review studies mentioned the self-blend (also known as the "à la carte" model) and the enriched virtual model. The first model allows students to take fully online courses with online teachers, in addition to other F2F courses. ${ }^{60}$ In the second model, students are asked to be able to conduct F2F sessions with instructors and then can complete their assignments online, but they are not required to attend $\mathrm{F} 2 \mathrm{~F}$ classes. ${ }^{60}$

Finally, only one study applied the mixed model, supplemental model and online practicing model. Specifically, in the mixed model, content delivery and practical activities occur both F2F and online. In the supplemental model, both content delivery and practical activities take place F2F. In contrast, in the online practicing model, students can practice activities through a specific online learning environment. In particular, the reported BL models were implemented differently in many domains. It should be noted that some studies investigated more than

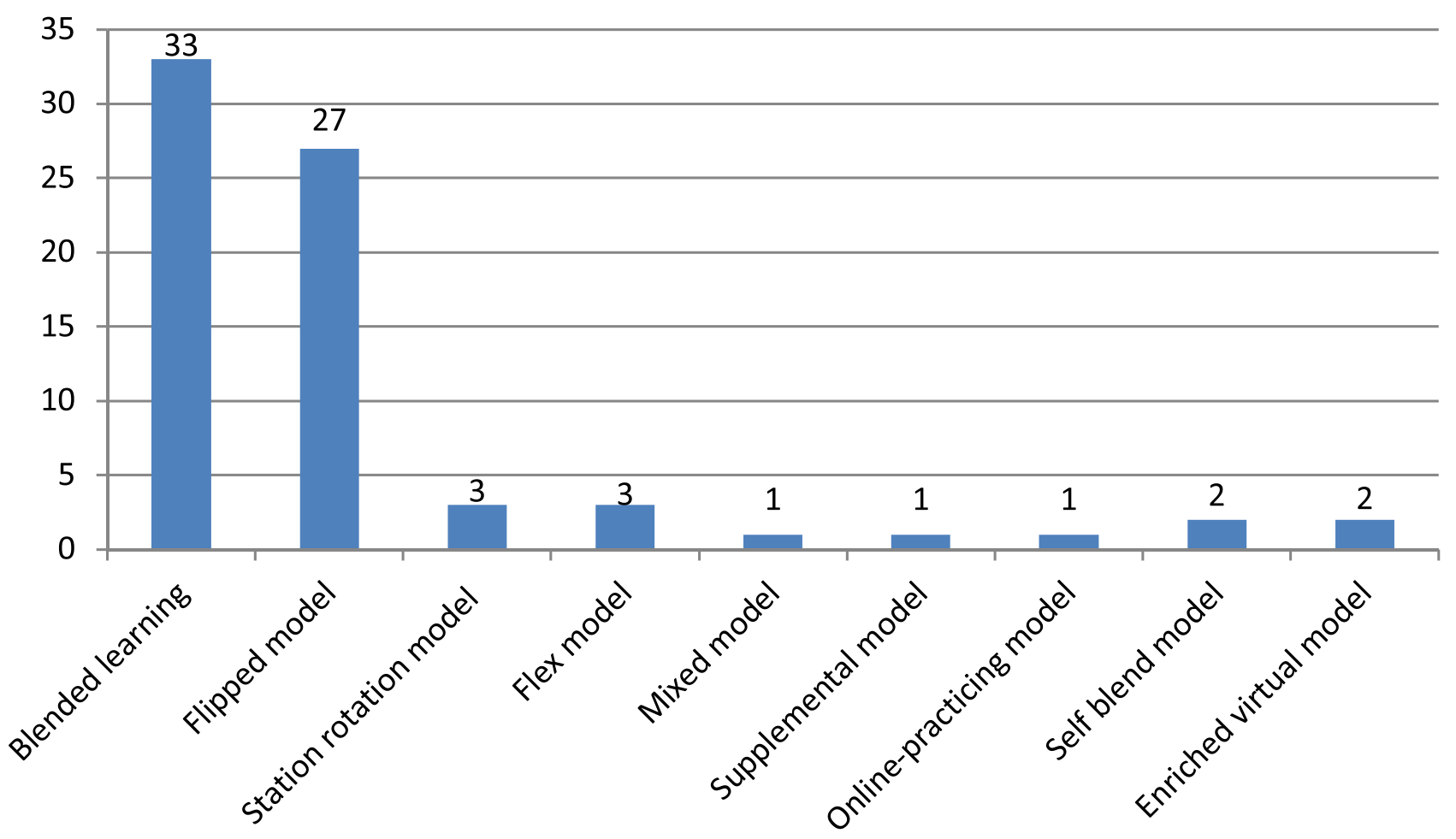

Figure 8 Frequency of usage of blended learning models. 
Table 4 Distribution of Studies by Blended Learning Models and Subject Area

\begin{tabular}{|c|c|c|c|c|c|c|c|c|c|c|}
\hline $\begin{array}{l}\text { Subject } \\
\text { Area }\end{array}$ & $\begin{array}{l}\text { Blended } \\
\text { Learning }\end{array}$ & $\begin{array}{c}\text { Flipped } \\
\text { Model }\end{array}$ & $\begin{array}{c}\text { Station } \\
\text { Rotation } \\
\text { Model }\end{array}$ & $\begin{array}{l}\text { Flex } \\
\text { Model }\end{array}$ & $\begin{array}{l}\text { Mixed } \\
\text { Model }\end{array}$ & $\begin{array}{c}\text { Supplemental } \\
\text { Model }\end{array}$ & $\begin{array}{c}\text { Online } \\
\text { Practicing } \\
\text { Model }\end{array}$ & $\begin{array}{l}\text { Self- } \\
\text { Blend } \\
\text { Model }\end{array}$ & $\begin{array}{c}\text { Enriched } \\
\text { Virtual } \\
\text { Model }\end{array}$ & Total \\
\hline $\begin{array}{l}\text { Multiple } \\
\text { courses }\end{array}$ & 7 & 7 & 0 & 0 & 0 & 0 & 0 & 0 & 0 & 14 \\
\hline Language & I & 2 & 0 & 0 & 0 & 0 & 0 & 0 & 0 & 3 \\
\hline Health & 8 & 7 & 1 & 0 & 0 & 0 & 0 & 0 & 0 & 16 \\
\hline $\begin{array}{l}\text { Teacher } \\
\text { Education }\end{array}$ & 2 & 0 & 0 & 0 & 0 & 0 & 0 & 0 & 0 & 2 \\
\hline STEM & 0 & 5 & 0 & I & I & I & I & 0 & 0 & 9 \\
\hline Uncategorized & 15 & 6 & 2 & 2 & & 0 & 0 & 2 & 2 & 29 \\
\hline Total & 33 & 27 & 3 & 3 & I & I & I & 2 & 2 & 73 \\
\hline
\end{tabular}

one BL model. For instance, Alammary investigated flipped, mixed, flex, supplemental, and online-practicing models. $^{59}$

Table 4 presents the distribution of the reviewed studies by BL models and subject areas. 22 studies (seven multiple courses and 15 uncategorized) have focused on the design of $\mathrm{BL}$ in general or in multiple courses. This might be explained by the fact that teachers have limited knowledge about BL models that is why they always face challenges on how to design their blended courses and mix the offline and online settings. ${ }^{58}$ This blended learning design problem was further emphasized during the COVID-19 pandemic, where several teachers raised concerns about this matter. ${ }^{61}$ Therefore, more BL design trainings should be provided for teachers to help them efficiently design their blended courses.

Additionally, the flipped model was frequently used in health (seven studies), followed by STEM (five studies). This may be explained by health and STEM subjects requiring many hands-on practices to promote skill acquisition and long-term retention by the student. ${ }^{62,63}$ In line with this, the flipped model enables teachers to reduce the in-class time by teaching all the courses online (in the preclass stage) and counterbalance the students' workload, so that the class time can be reserved for practical exercises instead of traditional lectures. For instance, in the health domain, the flipped model is applied by explaining the basic concepts of the course using different learning strategies in the pre-class stage, such as online learning platforms, instructional videos, animation, PowerPoint presentations and 3D virtual gaming situations. Also, students can use social media platforms such as Facebook for online discussions. In-class activities include instructor-led training, discussion of issues, practice or doing exercises (eg, assignments or quizzes), clinical teaching (eg, nursing diagnosis training) or lab teaching. In this context, several learning technologies were used, such as traditional computers and projectors, medical or teaching equipment and simulation teaching aids. Finally, in the post-class stage, some teachers used assessment methods to evaluate students' perception of the applied model using peer evaluation, post-class evaluation and surveys. Similarly, in STEM subjects, the in-class time was reserved for more practice, including complex exercises where students can interact with each other and with the instructor (collaborative group assignments), active learning exercises rather than lectures, gaming activities, examinations and peer instruction.

Furthermore, as Table 4 shows, the mixed, flex, supplemental and online practicing models were also applied in STEM, specifically in programming courses. ${ }^{59}$ This may be explained by the fact that STEM subjects - and programming courses in particular - allow for flexibility; combined with emerging technologies, this enables the teaching of this course in different ways, fully online or F2F. ${ }^{64}$ For instance, in the mixed model, students received the course content and practical coding exercises in both F2F and online sessions, reserving most of the in-class time for practical exercises and discussion. In this context, in addition to the classical learning strategies such as online self-paced learning, online collaboration and online instructor-led learning, online programming tools were 
also used for coding and problem solving in online sessions. In the flex model, both course content and practical coding exercises take place online, but students are required to attend $\mathrm{F} 2 \mathrm{~F}$ sessions from time to time to check their progress or be provided with feedback. In the supplemental model, both course content and practical coding exercises take place F2F. However, online supplemental activities are added to the course to increase students' engagement with course content. In the online practicing model, an online programming environment is used as the backbone of students' learning. It allows students to practice programming and problem solving and provides them with immediate feedback about their programming solutions. The delivery of the course content is achieved through lectures and/or self-based online resources. In some cases, online resources are integrated within the online programming environment.

\section{Outcomes and Challenges}

Figure 9 presents the different learning outcomes investigated in the 57 review studies based on two categories: psychological and behavioural outcomes. ${ }^{65}$ The majority of studies (49 studies) focused on investigating the psychological outcomes within the reviewed studies. Specifically, students' self-regulation toward learning was the most investigated psychological outcome (10 studies), followed by satisfaction (nine studies) and engagement (eight studies). According to Van Laer and Elen, blended learning design includes attributes that support self-regulation, including authenticity, personalization, learner control, scaffolding and interaction. ${ }^{66}$ The 10 studies found that students' self-regulation was improved. Additionally, BL was found to improve students' satisfaction and engagement in different domains, especially in health (seven studies). For instance, Li et $\mathrm{al}^{67}$ and Presti ${ }^{68}$ found that flipped learning enhanced students' engagement and satisfaction in nursing education. Moreover, motivation, attitude, high-order thinking, social interaction and self-efficacy were found to be improved using BL.

The most investigated behavioural outcome is academic performance (26 studies), followed by skill progression and cooperation. In particular, the 26 studies showed that BL supports learning performance in different subject areas, including health, language and STEM. BL can also enhance students' skills, such as clinical skills in the health domain,35,69 and speaking skills in the language domain. ${ }^{70}$ Additionally, its design may include several collaborative learning assignments (online or F2F) that encourage cooperation with students. ${ }^{71}$ It should be noted that some studies investigated more than one type of learning outcomes. For instance, Atmacasoy and Aksu investigated students' engagement with, collaboration in, participation in and academic performance with the blended learning course. ${ }^{72}$

Despite the many advantages that BL offers, it also comes with several challenges. Figure 10 presents the most encountered challenges in the 57 review studies. Specifically, the lack of ICT skills is the most mentioned challenge (seven studies), followed by infrastructure issues (six studies) such as internet-related problems and lack of personal computers, course preparation time (three studies), design model and cost of technologies (two studies for each) and course quality content, student engagement and student isolation (one study for each). It should be noted that 47 studies did not mention any challenges and nine studies mentioned more than one challenge each. For instance, Rasheed et al found that students, teachers and institutions may face different challenges in $\mathrm{BL}$, such as students' isolation, lack of ICT skills for teachers and students and technological provision challenges (eg, cost of online learning technologies) for institutions. ${ }^{73}$

Both teachers and students from different domains might lack ICT skills, which can negatively influence their adoption of BL. For instance, Atmacasoy and Aksu stated that teachers with low ICT skills may not have positive attitudes toward using BL since it is based on technology use. ${ }^{72}$ Teachers might find difficulties in the ease of use of some technologies while creating a BL course, such as in recording videos, uploading videos and using online learning platforms. ${ }^{73}$ Additionally, students may face some technological complexity challenges, such as accessing online educational resources or uploading their materials to the online learning environment. ${ }^{73}$

ICT infrastructure is also a crucial layer for facilitating and implementing blended courses; however, it is still a major problem for several universities, especially in developing countries ${ }^{74}$ and rural areas. ${ }^{75}$ For instance, a lack of basic technologies, including internet, computers and projectors can limit the implementation of blended courses. Therefore, it is very important to improve institutes' ICT infrastructure in order to improve education in general and enable teachers to teach using BL, which has proven to be efficient in many subject areas (see sections above).

In addition to issues with ICT skills and infrastructure, teachers may lack knowledge about designing BL models and hence face difficulties in selecting the appropriate design for their courses, ${ }^{58}$ and they may also spend too much time preparing the blended course. ${ }^{75,76}$ Moreover, 


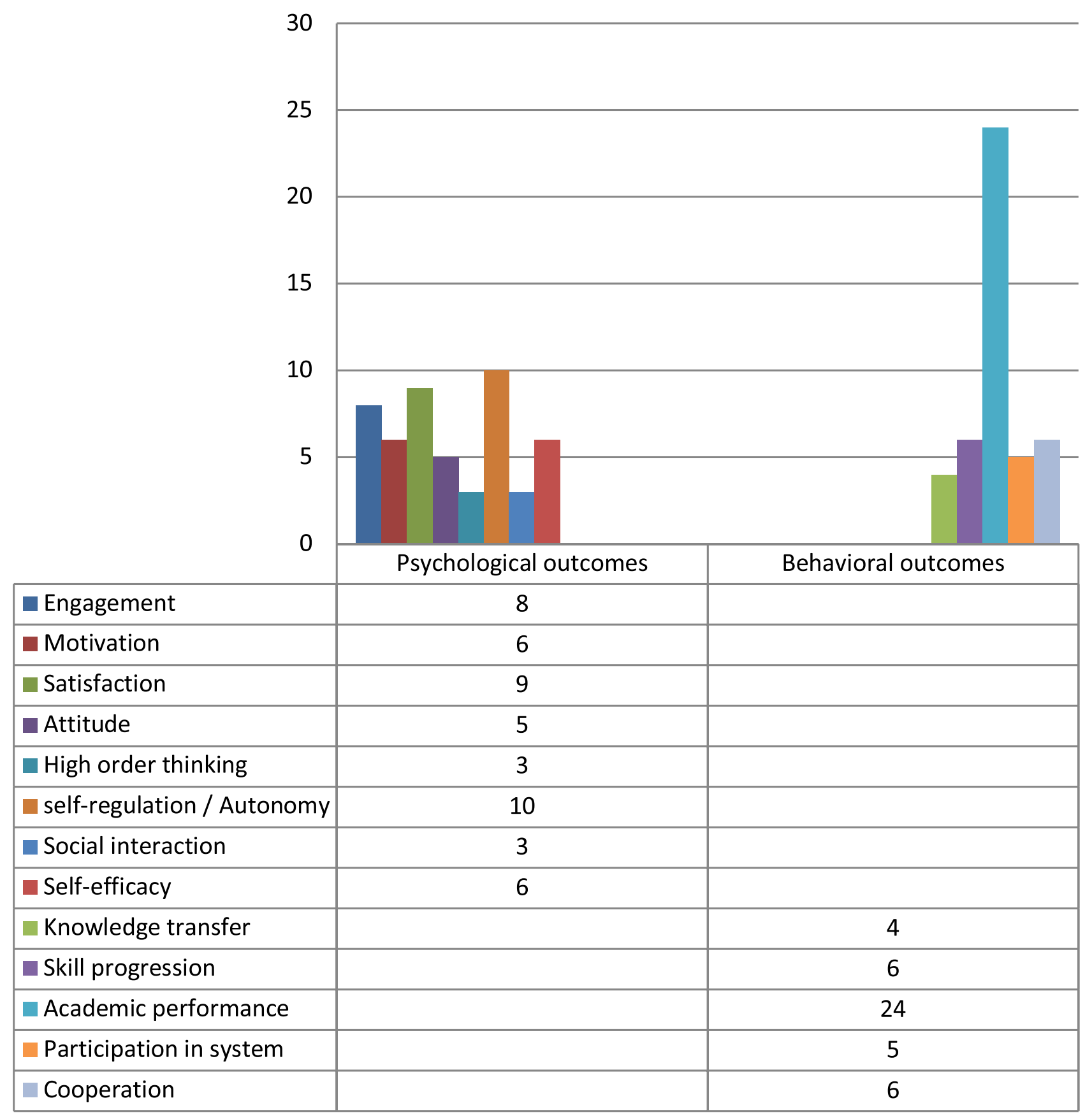

Figure 9 Distribution of learning outcomes based on the number of studies addressing them.

some challenges of online learning, such as engagement and students' isolation, may be faced in BL. In this context, teachers may integrate online collaborative assignments to solve the problem of isolation ${ }^{77}$ and integrate new approaches, such as gamification, into the online learning environment in order to make students motivated and engaged while learning online. ${ }^{78,79}$ In this context, Ekici found that gamified flipped learning enhanced students' motivation and engagement while learning. ${ }^{80}$

\section{Conclusion}

This study conducted a systematic review of systematic reviews on $\mathrm{BL}$. It revealed several findings according to each research question: (1) the first two systematic reviews on BL were conducted in 2012, and this number rapidly increased over the years, reflecting a massive interest in BL. Additionally, more cross-country collaboration should be established to facilitate BL implementation in countries that lack, for instance, infrastructure or the needed BL 


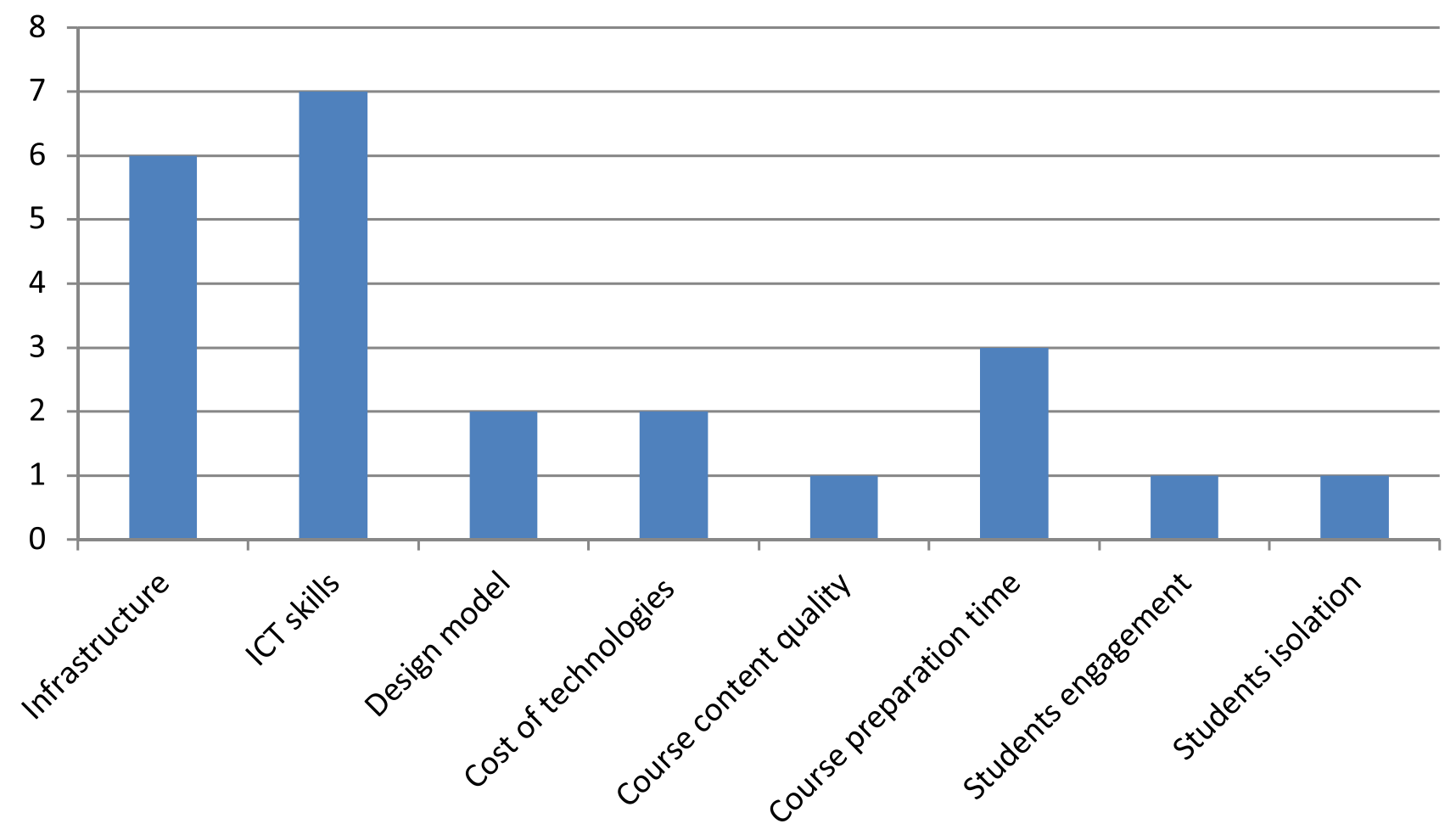

Figure 10 Distribution of blended learning challenges.

competencies; (2) despite that several studies focused on specific subject area such as health or STEM, most studies did not discuss BL from a specific subject area; (3) most of the studies targeted students as stakeholders, and neglected major key players for BL adoption, such as policy makers; (4) most of the studies conducted a systematic review with qualitative analysis. Therefore, future research should follow a more quantitative approach through meta-analysis in order to provide a better understanding of the nuanced effects of BL; (5) the majority of studies discussed BL as a generic construct and did not focus on the learning models of BL. However, the flipped model was the most frequently implemented model in the papers that focused on learning models specifically in health and STEM ; and (6) BL can affect students' psychological and behavioural outcomes. In terms of psychological outcomes, it can enhance students' self-regulation toward learning, satisfaction and engagement while learning in different domains, especially in health. In terms of behavioural outcomes, BL supported students' academic performance in different subject areas. Additionally, a lack of ICT skills and infrastructure are the most encountered challenges by teachers, students and institutions.

The findings of this study can help create a roadmap about future research on BL. This could facilitate BL adoption worldwide and thus contribute to achieving the UN Sustainable Development Goals (SDGs), especially SDG \#4 - equity and high-quality education for all - which works as a backbone for some other SDGs, such as good health (\#3), economic Growth (\#8) and reduced inequality (\#10). Despite the importance of the revealed findings, this study has several limitations that should be acknowledged. For instance, this study used a limited number of search keywords within specific electronic databases.

Future research might focus on: (1) dealing with these limitations; (2) investigating different BL models with specific application domains to test their impacts on students' psychological and behavioural outcomes; (3) enhancing students' motivation and engagement in online sessions by integrating new motivational concepts such as gamification in online learning platforms; and (4) dealing with BL challenges by providing some solutions to enhance the learning experience. For instance, for the challenge of a lack of ICT skills, research might work to provide ICT trainings for teachers and students to enhance their skills with technology.

\section{Acknowledgments}

The study was supported by the National Natural Science Foundation of China (The Research Fund for International 
Young Scientists; Grant No. 71950410624). However, any opinions, findings, and conclusions or recommendations expressed in this article are those of the authors and do not necessarily reflect the views of the National Natural Science Foundation of China.

\section{Disclosure}

The authors report no conflicts of interest in this work.

\section{References}

1. Dakhi O, Irfan D. Blended learning: a 21st century learning model at college. Int J Multi Sci. 2020;1(08):50-65.

2. Hrastinski S. What do we mean by blended learning? TechTrends. 2019;63(5):564-569. doi:10.1007/s11528-019-00375-5

3. Lai CL, Hwang GJ. A self-regulated flipped classroom approach to improving students' learning performance in a mathematics course. Comput Educ. 2016;100:126-140. doi:10.1016/j.compedu.2016. 05.006

4. Seraji F, Attaran M, Azizi SM. Blended learning researches in Iran: several fundamental criticisms. Digit Educ Rev. 2019;(36):190-206. doi:10.1344/der.2019.36.190-206

5. Zhang LC, Worthington AC, Hu M. Cost economies in the provision of higher education for international students: Australian evidence. High Educ. 2016;74(4):717-734. doi:10.1007/s10734-016-0078-9

6. Malczyk BR. Introducing social work to HyFlex blended learning: a student-centered approach. J Teach Soc Work. 2019;39(4):414-428. doi:10.1080/08841233.2019.1652226

7. Bonk CJ, Graham CR. The Handbook of Blended Learning: Global Perspectives, Local Designs. John Wiley \& Sons; 2012.

8. Owston R, York DN, Malhotra T. Blended learning in large enrolment courses: student perceptions across four different instructional models. Australas J Educ Technol. 2019;35(5):29-45.

9. Seraji F. What differences? Thematic analyses of blended learning researches in Iran. Open Learn. 2020;1-18. doi:10.1080/ 02680513.2020.1803820

10. Garrison DR, Kanuka H. Blended learning: uncovering its transformative potential in higher education. Internet High Educ. 2004;7 (2):95-105. doi:10.1016/j.iheduc.2004.02.001

11. Brame CJ, Perez KE. Effective educational videos: principles and guidelines for maximizing student learning from video content. $C B E$ Life Sci Educ. 2016;15(4):1-6. doi:10.1187/cbe.16-03-0125

12. Al-Samarraie H, Saeed N. A systematic review of cloud computing tools for collaborative learning: opportunities and challenges to the blended-learning environment. Comput Educ. 2018;124:77-91. doi:10.1016/j.compedu.2018.05.016

13. Hewitt L. Timing is flipping everything: a case study in law that suggests student engagement depends on when the flipped classroom is introduced. Compass J Learn Teach. 2017;10(1):1-8.

14. Quarato S. Is the Flipped Classroom Pedagogy Effective for All Students? [Unpublished Certificate of Advanced Study Thesis]. Sacred Heart University; 2016.

15. Nielsen L. Five reasons I'm not flipping over the flipped classroom. Technol Learn. 2011;32:46.

16. Huang R, Tlili A, Wang $\mathrm{H}$, et al. Emergence of the online-mergeoffline (OMO) learning wave in the post-COVID-19 era: a pilot study. Sustainability. 2021;13(6):3512. doi:10.3390/su13063512

17. Rachmadtullah R, Marianus Subandowo R, Humaira MA, Aliyyah RR, Samsudin A, Nurtanto M. Use of blended learning with moodle: study effectiveness in elementary school teacher education students during the COVID-19 pandemic. Int J Adv Sci Technol. 2020;29 (7):3272-3277.
18. UNESCO, ILO. Supporting teachers in back-to-school efforts. Guidance for policy-makers. International task force on teachers for education 2030; 2020. Available from: https://unesdoc.unesco.org/ ark:/48223/pf0000373479. Accessed September 21, 2021.

19. Chang CY, Lai CL, Hwang GJ. Trends and research issues of mobile learning studies in nursing education: a review of academic publications from 1971 to 2016. Comput Educ. 2018;116:28-48. doi:10.101 6/j.compedu.2017.09.001

20. Höffler TN, Leutner D. Instructional animation versus static pictures: a meta-analysis. Learn Instruct. 2007;17(6):722-738. doi:10.1016/j. learninstruc.2007.09.013

21. Tlili A, Lin V, Chen NS, Huang R. A systematic review on robotassisted special education from the activity theory perspective. Educ Technol Soc. 2020;23(3):95-109.

22. Smith V, Devane D, Begley CM, Clarke M. Methodology in conducting a systematic review of systematic reviews of healthcare interventions. BMC Med Res Methodol. 2011;11(1):1-6. doi:10.1186/1471-2288-11-15

23. Cahapay MB. Rethinking education in the new normal post-COVID19 era: a curriculum studies perspective. Aquademia. 2020;4:2. doi:10.29333/aquademia/8315

24. Kitchenham B, Brereton P. A systematic review of systematic review process research in software engineering. Info Softw Technol. 2013;55(12):2049-2075. doi:10.1016/j.infsof.2013.07.010

25. Marcolino MS, Oliveira JAQ, D'Agostino M, Ribeiro AL, Alkmim MBM, Novillo-Ortiz D. The impact of mHealth interventions: systematic review of systematic reviews. JMIR mHealth uHealth. 2018;6 (1):e23. doi:10.2196/mhealth. 8873

26. Pahlevan-Sharif S, Mura P, Wijesinghe SN. A systematic review of systematic reviews in tourism. J Hospital Tour Manag. 2019;39:158165. doi:10.1016/j.jhtm.2019.04.001

27. Castro-Gil R, Correa D. Transparency in previous literature reviews about blended learning in higher education. Educ Info Technol. 2021;26:1-28.

28. Moher D, Liberati A, Tetzlaff J, Altman DG. Preferred reporting items for systematic reviews and meta-analyses: the PRISMA statement. Int J Surg. 2010;8(5):336-341. doi:10.1016/j.ijsu.2010.02.007

29. Harzing AW, Alakangas S. Google scholar, scopus and the web of science: a longitudinal and cross-disciplinary comparison. Scientometrics. 2016;106(2):787-804. doi:10.1007/s11192-015-1798-9

30. Kim HR, Choi CH, Jo E. A methodological quality assessment of metaanalysis studies in dance therapy using AMSTAR and AMSTAR 2. Healthcare. 2020;8(4):446. doi:10.3390/healthcare 8040446

31. Hsu YC, Ho HNJ, Tsai CC, et al. Research trends in technology based learning from 2000 to 2009: a content analysis of publications in selected journals. J Educ Technol Soc. 2012;15(2):354-370.

32. Lin HC, Hwang GJ. Research trends of flipped classroom studies for medical courses: a review of journal publications from 2008 to 2017 based on the technology-enhanced learning model. Interact Learn Environ. 2018. doi:10.1080/10494820.2018.1467462

33. Yang QF, Lin CJ, Hwang GJ. Research focuses and findings of flipping mathematics classes: a review of journal publications based on the technology-enhanced learning model. Interact Learn Environ. 2019. doi:10.1080/10494820.2019.1637351

34. Keengwe J, Kang KK. Blended learning in teacher preparation programs: a literature review. Int J Info Commun Technol Educ. 2012;8 (2):81-93. doi:10.4018/jicte.2012040107

35. Rowe M, Frantz J, Bozalek V. The role of blended learning in the clinical education of healthcare students: a systematic review. Med Teach. 2012;34(4):e216-e221. doi:10.3109/0142159X.2012.642831

36. Raja R, Nagasubramani PC. Impact of modern technology in education. J Appl Adv Res. 2018;3(1):33-35. doi:10.21839/jaar.2018. v3iS1.165

37. Sar A, Misra SN. An empirical study to examine the components of technology-enabled distance education affecting students' perception. Mater Today. 2020. doi:10.1016/j.matpr.2020.10.781 
38. Owston R. Blended learning policy and implementation: introduction to the special issue. Internet High Educ. 2013;18:1-3. doi:10.1016/j. iheduc.2013.03.002

39. Jun L. The policy and strategy for blended learning in a Chinese open university. In: Cheung SKS, Fong J, Kwok LF, Li K, Kwan R, editors. Hybrid Learning. Springer;2012. doi:10.1007/978-3-64232018-7 32

40. Birgili B, Seggie FN, Oğuz E. The trends and outcomes of flipped learning research between 2012 and 2018: a descriptive content analysis. J Comput Educ. 2021;8:1-30.

41. Wang Y, Han X, Yang J. Revisiting the blended learning literature: using a complex adaptive systems framework. Educ Technol Soc. 2015;18(2):380-393.

42. Soler R, Soler JR, Araya I. Subjects in the blended learning model design. Theoretical-methodological elements. Procedia. 2017;237:771-777. doi:10.1016/j.sbspro.2017.02.120

43. Walker S, Dwyer T, Moxham L, Broadbent M, Sander T. Facilitator versus preceptor: which offers the best support to undergraduate nursing students? Nurse Educ Today. 2013;33(5):530-535. doi:10.1016/j.nedt.2011.12.005

44. Yeonja C, Eunju S, Oh E. Effects of teaching communication skills using a video clip on a smart phone on communication competence and emotional intelligence in nursing students. Arch Psychiatr Nurs. 2015;29(2):90-95. doi:10.1016/j.apnu.2014.11.003

45. Boelens R, De Wever B, Voet M. Four key challenges to the design of BLENDED learning: a systematic literature review. Educ Res Rev. 2017;22:1-18. doi:10.1016/j.edurev.2017.06.001

46. GMIT. Blended and online learning policies. Galway-Mayo Institute of Technology; 2018. Available from: https://www.gmit.ie/sites/ default/files/public/directorate-communications/docs/strategic-planrevision-2013-16.pdf. Accessed September 21, 2021.

47. University of the West Indies. Blended learning policies. blendedlearning-policy.aspx (uwi.edu). October 9, 2014.

48. Halverson LR, Graham CR, Spring KJ, Drysdale JS. An analysis of high impact scholarship and publication trends in blended learning. Dist Educ. 2012;33(3):381-413. doi:10.1080/01587919.2012.723166

49. Drysdale JS, Graham CR, Spring KJ, Halverson LR. An analysis of research trends in dissertations and theses studying blended learning. Internet High Educ. 2013;17:90-100. doi:10.1016/j.iheduc. 2012.11.003

50. Zimmerman BJ, Schunk DH. Self-regulated learning and performance: an introduction and an overview. In: Zimmerman BJ, Schunk DH, editors. Handbook of Self-Regulation of Learning and Performance. Routledge; 2011:1-12.

51. Means B, Toyama Y, Murphy R, Bakia M, Jones K. Evaluation of Evidence-Based Practices in Online Learning: A Meta-Analysis and Review of Online Learning Studies. Washington: U.S. Department of Education, Office of Planning, Evaluation, and Policy Development; 2009.

52. Owston RD, Sinclair M, Wideman H. Blended learning for professional development: an evaluation of a program for middle school mathematics and science teachers. Teach Coll Rec. 2008;110 (5):1033-1064.

53. Young A, Lewis CW. Teacher education programmes delivered at a distance: an examination of distance student perceptions. $J$ Teach Teach Educ. 2008;24(3):601-609. doi:10.1016/j.tate.2007.03.003

54. Cooper HM. Research Synthesis and Meta-Analysis: A Step-By-Step Approach. 4th ed. SAGE Publications; 2010.

55. Cooper HM, Hedges LV, Valentine JC. The Handbook of Research Synthesis and Meta-Analysis. 2nd ed. Russell Sage Foundation; 2009.

56. Liberati A, Altman DG, Tetzlaff J, Mulrow C, Gøtzsche PC, Ioannidis JPA. The PRISMA statement for reporting systematic reviews and meta-analyses of studies that evaluate health care interventions: explanation and elaboration. J Clin Epidemiol. 2009;62 (10):1-34. doi:10.1016/j.jclinepi.2009.06.006
57. Liu Q, Peng W, Zhang F, Hu R, Li Y, Yan W. The effectiveness of blended learning in health professions: systematic review and metaanalysis. J Med Internet Res. 2016;18(1):e4807. doi:10.2196/ jmir.4807

58. Coyle KK, Chambers BD, Anderson PM, Firpo-Triplett R, Waterman EA. Blended learning for sexual health education: evidence base, promising practices, and potential challenges. $J$ Schl Health. 2019;89(10):847-859. doi:10.1111/josh.12821

59. Alammary A, Edward K-L. Blended learning models for introductory programming courses: a systematic review. PLoS One. 2019;14(9): e0221765. doi:10.1371/journal.pone.0221765

60. Krismadinata K, Verawardina U, Jalinus N, et al. Blended learning as instructional model in VOCATIONAL education: literature review. Univers J Educ Res. 2020;8(11B):5801-5815. doi:10.13189/ ujer.2020.082214

61. Denden M, Tlili A, Burgos D, et al. Framework for teacher support during remote teaching in a crisis: Covid-19, as a case study. In Radical Solutions for Education in a Crisis Context. Springer; 2020:147-161.

62. Burgess A, van Diggele C, Roberts C, Mellis C. Tips for teaching procedural skills. BMC Med Educ. 2020;20(S2). doi:10.1186/s12909020-02284-1

63. National Research Council. Practices that support effective STEM education. In: Successful STEM Education: A Workshop Summary. Washington, DC: The National Academies Press; 2011.

64. Gordon NA. Flexible learning in computer science. $N$ Direct Teach Phys Sci. 2016;(11). doi:10.29311/ndtps.v0i11.575

65. Majuri J, Koivisto J, Hamari J. Gamification of education and learning: a review of empirical literature. In The 2nd International GamiFIN Conference; Pori, Finland; 2018:21-23.

66. Van Laer S, Elen J. In search of attributes that support self-regulation in blended learning environments. Educ Info Technol. 2016;22 (4):1395-1454. doi:10.1007/s10639-016-9505-X

67. Li BZ, Cao NW, Ren CX, Chu XJ, Zhou HY, Guo B. Flipped classroom improves nursing students' theoretical learning in China: a metaanalysis. PLoS One. 2020;15(8). doi:10.1371/journal.pone.0237926

68. Presti CR. The flipped learning approach in nursing education: a literature review. J Nurs Educ. 2016;55(5):252-257. doi:10.3928/ 01484834-20160414-03

69. Coyne E, Rands H, Frommolt V, Kain V, Plugge M, Mitchell M. Investigation of blended learning video resources to teach health students clinical skills: an integrative review. Nurse Educ Today. 2018;63:101-107. doi:10.1016/j.nedt.2018.01.021

70. Turan Z, Akdag-Cimen B. Flipped classroom in English language teaching: a systematic review. Comput Assist Lang Learn. 2019;33 (5-6):590-606. doi:10.1080/09588221.2019.1584117

71. Yaman M, Graf D. Evaluation of an international blended learning cooperation project in biology teacher education. Turk Online J Educ Technol. 2010;9(2):87-96.

72. Atmacasoy A, Aksu M. Blended learning at pre-service teacher education in Turkey: a systematic review. Educ Info Technol. 2018;23(6):2399-2422. doi:10.1007/s10639-018-9723-5

73. Rasheed RA, Kamsin A, Abdullah NA. Challenges in the online component of blended learning: a systematic review. Comput Educ. 2020;144:103701. doi:10.1016/j.compedu.2019.103701

74. Kozma RB, Vota WS. ICT in developing countries: policies, implementation, and impact. In: Handbook of Research on Educational Communications and Technology. Springer; 2014:885-894.

75. Ho WY. A review of blended synchronous learning. Int J Soc Media Interact Learn Environ. 2017;5(4):278-291. doi:10.1504/IJSMILE. 2017.090977

76. Chan RH, Quek CL. Benefits, challenges and strategies of implementing blended learning in tertiary institutes. Int J Soc Media Interact Learn Environ. 2014;2(3):285-300. doi:10.1504/ IJSMILE.2014.064215 
77. Blau I, Shamir-Inbal T, Avdiel O. How does the pedagogical design of a technology-enhanced collaborative academic course promote digital literacies, self-regulation, and perceived learning of students? Internet High Educ. 2020;45:100722. doi:10.1016/j.iheduc.2019. 100722

78. Denden M, Tlili A, Essalmi F, Jemni M. Students' learning performance in a gamified and self-determined learning environment. In 2020 International Multi-Conference on: "Organization of Knowledge and Advanced Technologies"(OCTA); IEEE; 2020:1-5.
79. Tlili A, Denden M, Essalmi F, Jemni M, Huang R, Chang TW. Personality effects on students' intrinsic motivation in a gamified learning environment. In 19th International Conference on Advanced Learning Technologies (ICALT); IEEE; 2019: 2161, 100-102.

80. Ekici M. A systematic review of the use of gamification in flipped learning. Educ Info Technol. 2021;26:1-20.

\section{Publish your work in this journal}

Psychology Research and Behavior Management is an international, peer-reviewed, open access journal focusing on the science of psychology and its application in behavior management to develop improved outcomes in the clinical, educational, sports and business arenas. Specific topics covered in the journal include: Neuroscience, memory and decision making; Behavior modification and management; Clinical applications; Business and sports performance management; Social and developmental studies; Animal studies. The manuscript management system is completely online and includes a very quick and fair peer-review system, which is all easy to use. Visit http://www. dovepress.com/testimonials.php to read real quotes from published authors.

Submit your manuscript here: https://www.dovepress.com/psychology-research-and-behavior-management-journal 